\title{
Lessons for the COVID-19 response from a multidrug- resistant tuberculosis study in South Africa: How public health promotion can reach vulnerable young women
}

\author{
PC Mugoni, PhD \\ Howard College, University of KwaZulu-Natal, Durban, South Africa \\ Corresponding author: PCMugoni (pcmugoni@gmail.com)
}

Background. As the world grapples with the COVID-19 pandemic, lessons from responding to diseases that are endemic to Africa, such as HIV/AIDS, malaria, yellow fever, Lassa fever and Ebola, can inform responses to the new challenge. Gaps in and successes of South Africa $(\mathrm{SA})^{\prime}$ 's established tuberculosis (TB) management programme have potential to inform COVID-19 responses.

Objectives. To present the findings of a 2019 study that assessed how communication can contribute to improving health outcomes among young women with multidrug-resistant TB (MDR-TB) in SA.

Methods. Primary qualitative data were collected from 20 purposefully selected participants in eThekwini Metro, KwaZulu-Natal Province. Data were collected through focus group discussions with women with MDR-TB, and key informant interviews with their family members, health workers and KwaZulu-Natal health department personnel.

Results. The study assessed how age, gender, socioeconomic status, geographic location and comorbidity converge to influence susceptibility to communicable diseases and risk of mortality, and proposes that vulnerabilty factors be incorporated into both MDR-TB and COVID-19 responses.

Conclusion. In the early stages of the COVID-19 pandemic, much is unknown about the incubation period and infection transmission modes, and there have been suggestions that asymptomatic people may be infectious. In highly populated urban areas, television and radio (local soap operas, dramas and hard news programmes), social media (Facebook and WhatsApp) and information from children are the best mediums for reaching young women to provide integrated public health education about both MDR-TB and COVID-19.

On 31 December 2019, China reported pneumonic disease of unknown origin in Wuhan, Hubei Province. On 11 January 2020, the World Health Organization (WHO) announced that a previously unknown type of coronavirus was responsible for the outbreak. Once identified, the virus was named severe acute respiratory syndrome coronavirus 2 (SARS-CoV-2), part of a family of viruses that causes severe acute respiratory syndrome (SARS) and Middle East respiratory syndrome (MERS). The disease caused by SARS-CoV-2 was named COVID-19. It has ultimately spread to most countries in the world. ${ }^{[1]}$ The spread was swift; Thailand confirmed its first case - a person who had travelled from Wuhan - on 13 January. While a lot was still unknown about the aetiology of SARSCoV-2 rates of infection and vulnerability factors, by 20 January China's National Health Commission could confirm that humanto-human transmission via droplets and direct contact had been observed. ${ }^{[1]}$ The WHO's International Health Regulations Emergency Committee declared the SARS-CoV-2 outbreak the sixth public health emergency of international concern on 30 January 2020.[1]
People with COVID-19 continued to travel from Asia to Europe and the USA, introducing cases there in January and February 2020. African countries tracked the pandemic and prepared to act once the first cases were identified. They improved airport surveillance, implemented temperature screening at ports of entry and launched public health promotion campaigns. ${ }^{[2,3]}$ Countries such as the Democratic Republic of Congo, Nigeria and Tanzania based their responses on Ebola surveillance infrastructure and lessons learnt from responding to that disease. ${ }^{[2,4]}$

Africa did not have to wait long. Egypt confirmed the first imported case of SARS-COV-2 in its territory, and in Africa, on 14 February. ${ }^{[3]}$ A few days later, on 11 March, the WHO declared COVID-19 a global pandemic. The numbers of imported cases identified rose swiftly, and community transmission in Africa took root. By 7 April, 51 African countries had recorded 7092 cases of the disease that experts globally were calling the most serious global health threat resulting from a respiratory virus since the 1918 influenza pandemic. ${ }^{[1]}$ 


\section{RESEARCH}

South Africa (SA) confirmed the first person with SARS-CoV-2 in the country, a man who had arrived from Italy along with nine others, on 5 March. ${ }^{[5]}$ By 20 April, 121510 tests had yielded 3300 people with positive results, the largest number in Africa. ${ }^{[6]}$ Some 1055 people had recovered, and 58 had died. ${ }^{[6]}$ Two weeks earlier, SA had launched a mass screening and testing drive to increase active case-finding through thousands of community healthcare workers in areas where hotspots were being monitored through mobile phone-based geomapping technology. ${ }^{[6,7]}$ It was anticipated that the result of this strategy would be higher numbers of confirmed cases that would be observed during the week beginning 27 April. ${ }^{[7]}$

It is important to note that the reasons for low numbers of COVID-19 cases in some African countries, including the populous nation of Nigeria, are contested. Some argue that these trends can be accounted for by low national preparedness and capacities to test, and do not necessarily reflect fewer infections, ${ }^{\left[{ }^{[8]}\right.}$ while others concede that the pandemic is new and developing so fast that nothing definitive can be known. ${ }^{[3,8]}$ While these considerations are interesting and worth pursuing, they are outside the scope of this article to fully engage with.

Scholars suggest that African countries' experiences of the COVID-19 pandemic will likely differ from those of Europe (Spain and Italy) and China, where higher numbers of deaths of older people were recorded, because the demographics and living conditions are different. ${ }^{[9]}$ Africa has a younger population and a youth bulge, and higher levels of deprivation and malnutrition, which contribute to immunosupression. ${ }^{[9]}$ Youths are more likely to be unemployed or employed in the informal sector, which will be affected by slowdowns in economies. ${ }^{\left[{ }^{[9]}\right.}$ Further, many young people in urban areas live in overcrowded homes with elderly relatives, and find it challenging to implement public health recommendations to self-isolate when ill, or to stay home. ${ }^{[9]}$

SA, like other countries in southern Africa, has significant HIV and tuberculosis (TB) burdens. The established TB management programme has the potential to inform COVID-19 responses. TB is the leading cause of mortality in SA. ${ }^{[10]}$ Indeed, the country reports drug-resistant TB (DR-TB) figures that are well above the 200 cases per 100000 popultion that the WHO uses to pronounce a public health epidemic. ${ }^{[1]}$ KwaZulu-Natal Province (KZN), where the first two cases of COVID-19 in SA were confirmed, is inundated by rapidly rising DR-TB rates. ${ }^{[12,13]}$ Most new DR-TB infections in the province result from 'primary resistance', where already resistant TB strains are transmitted to others who have no history of TB infection or of being treated with anti-TB drugs. ${ }^{[12,13]}$

The elevated incidence of primary infections is suggestive of insufficient public knowledge about TB infection and prevention practices at household level and in community settings in both people with TB and those without. Despite significant investments in the clinical aspects of SA's TB programme, scholars aver that TB information is not widely or commonly available, and that universal misconceptions about TB remain prevalent, especially among people who do not have or have never had TB. ${ }^{[13,14]}$ Some claim that this results in personal protection knowledge and practice deficiencies among individuals, who remain vulnerable to contracting MDR-TB. ${ }^{[13]}$

\section{Objectives and questions}

The present study assessed how best to implement public health promotion to reach vulnerable young women with information that they will access, retain, share and discuss with others in their primary circles. One of the research questions was: How do young women in eThekwini Metro, KZN, receive information about MDR-TB accessed via television and radio and interpersonal communication?

The objectives of the research were to:

- establish the forms of mass-mediated messages frequently accessed by young women and their contacts about treatment for MDR-TB in eThekwini Metro

- ascertain which people, or groups of people, in contact with vulnerable young women receiving treatment for MDR-TB via public health facilities have the most reported influence in terms of communicating behaviour change and health information.

\section{Methods \\ Setting}

KZN is the second-most populous of SA's nine provinces, with 10.9 million people (19.9\% of the total population). ${ }^{[15]} \mathrm{KZN}$ is the epicentre of the TB, MDR-TB and HIV/AIDS crises in SA. ${ }^{[12,16]}$ A prospective study based on hospital admission data showed that from 2011 to 2017, MDR-TB incidence increased by 400\%. ${ }^{[16]}$ It is also significant that treatment outcomes for patients in KZN are markedly worse than those recorded in MDR-TB cohorts in other provinces. ${ }^{[13]}$ The challenge is so significant that researchers aver that successes in the DR-TB programme in KZN are pivotal to SA's ability to turn the tide on new infections.

KZN also hosts a dual HIV epidemic; more than $75 \%$ of people with all forms of TB in the province are also living with HIV..$^{[12,16]}$ Indeed, SA, and KZN in particular, have the largest HIV/TB/DR-TB syndemic globally. ${ }^{[12,17]}$ HIV and MDR-TB - and now HIV, TB and COVID-19 - in SA are uroboros-like. HIV-associated TB complicates TB management efforts, and TB comorbidity both complicates COVID-19 diagnosis and is correlated with worse outcomes among people with COVID-19, as explained later in this article. The burden on individuals receiving biomedical treatment for three or more serious communicable diseases needs to be considered in areas with syndemics.

KZN comprises 11 districts, one of which is eThekwini Metro (including the city of Durban and surrounding areas), which was the site of the present study. eThekwini is a largely densely populated urban municipality, which is bordered by some rural communities. These outlying areas are mostly underserved in terms of access to health infrastructure. ${ }^{[18]}$ A population of 3.6 million ethnically diverse people reside in the metro. Approximately $68 \%$ of the population is black, 20\% Indian, 9\% white and 3\% coloured. ${ }^{[15]}$ Official statistics indicate that females made up 52\% of the population in 2015, ${ }^{[15]}$ a figure that went down to 51\% in 2016, as indicated in Fig. 1. Unemployment is high (19\%), and official statistics show that the average annual household income was ZAR44 391 (approximately USD3 282.88 using a rate of USD1/ ZAR13.50) ${ }^{[15]}$ 


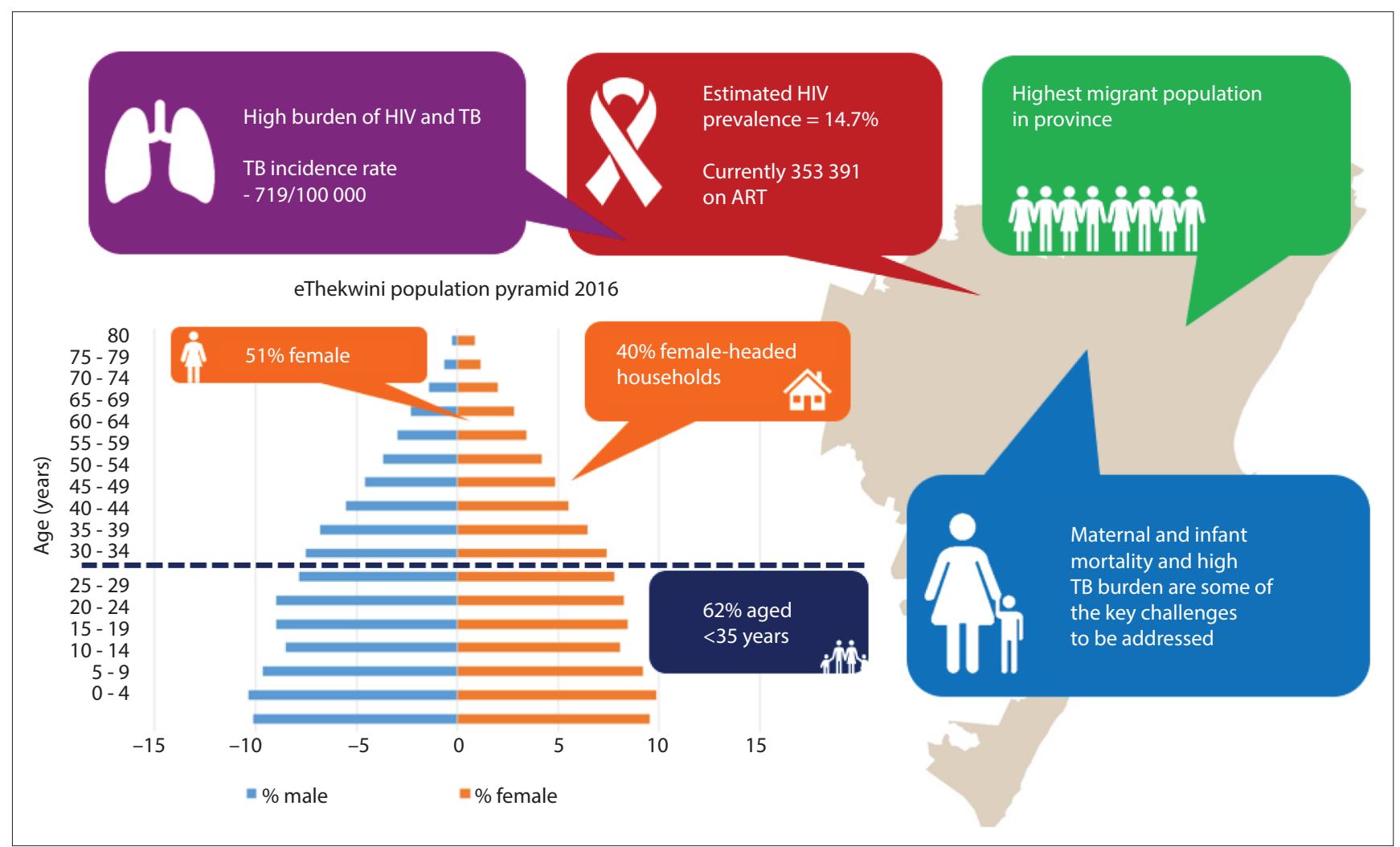

Fig. 1. Demographics of eThekwini Metro (2016). (TB = tuberculosis; $A R T=$ antiretroviral therapy).

About 9.3 million residents of KZN do not have health insurance and rely on the public health system. ${ }^{[18]}$ The highest proportion (26.7\%) of those using the public health system live in eThekwini Metro. ${ }^{[18]}$ The provincial, district and municipal health systems are overstretched by the significant MDR-TB challenge, not to mention TB, HIV and extensively drug-resistant TB, and now COVID-19. All these diseases fall squarely on the Provincial Department of Health and municipal authorities to manage.

\section{Conceptual framework}

The study's conceptual framework was designed to probe links among contextual motivations for young women's health behaviours, mass media use and preferences, as well as opportunities to improve health promotion in public health programmes in low socioeconomic contexts. The framework incorporated Flaskerud and Winslow's vulnerable populations conceptual model (VPCM) ${ }^{[19]}$ and Lazarsfeld and Katz's two-step flow theory ${ }^{[20]}$ and its later interpretations as the multi-step flow and one-step flow models. ${ }^{[21]}$

The VPCM encourages public health research to categorise people into 'populations' to better understand differences in their health needs, as the first step in designing responses to meet them. There is increasing acknowledgement of the importance of vulnerability in understanding how diseases affect different groups, and applying the knowledge to public health practice. ${ }^{[1,22,23]}$ Vulnerable populations are 'a social ensemble with an increased risk or disposition to unfavourable health outcomes. ${ }^{\text {[19] }}$ They are penurious, marginalised and stigmatised. ${ }^{[19]}$ Women and children, cultural and racial minorities and inhabitants of rural areas are vulnerable to poorer healthcare access and outcomes. Being an immigrant and multimorbidity also exacerbate vulnerability. ${ }^{[24]}$ Although black women in SA are part of the majority racial group, the historical and contemporary disenfranchisement of the country's black people during apartheid resulted in marginalisation in access to education, economic participation and quality healthcare (including TB care), which persists in current times. ${ }^{[25]}$ This translates into vulnerable populations in the country being more likely to be part of the majority racial group. ${ }^{[14]}$

Scholars note that vulnerability is intersectoral and caused by a 'multiplicity of risk factors that are often clustered together and acting synergistically in the same individual!'[26] This is already evident in the COVID-19 pandemic in SA, as explained later in this section. Sex and gender are important risk factors through which to probe different groups' relative risk to diseases and their access to and use of health systems. Socially and culturally ascribed roles and responsibilities of men and women in different communities influence their vulnerability to ill health, and their access to quality care, health resources, information and preventive and therapeutic services. ${ }^{[27]}$ Social, economic and biological determinants and consequences of diseases further result in different approaches to prevention, treatment, coping mechanisms, and health outcomes among men and women in the same context, and these need to be considered in health responses. ${ }^{[23]}$

Global COVID-19 data indicate that chronic respiratory and cardiovascular diseases, diabetes mellitus ${ }^{[28]}$ and lung damage caused by TB increase individual susceptibility to SARS-CoV-2. ${ }^{[29]}$ 


\section{RESEARCH}

TB is the leading cause of death among men in SA, while diabetes is the number one killer of women. Evidence from China, France, Germany, Iran, Italy, South Korea, Spain and the UK suggests that while COVID-19 infection rates are level among men and women, men are more likely to have serious disease and to die from COVID-19. ${ }^{[30]}$ A similar trend is emerging in data reported for $\mathrm{SA}^{\left[{ }^{[3]} \text { It }\right.}$ is, however, anticipated that women will be disproportionately susceptible to contracting SARS-CoV-2 because of their greater participation in clinical healthcare, and as domestic and community caregivers. ${ }^{[32]}$

Researchers propose that the observed differences in mortality between men and women can be accounted for by sex-based immunological or gendered differences, such as patterns and prevalence of smoking, socialisation trends and health-seeking behaviour, but caution against early assumptions because research in this area is ongoing. ${ }^{[32,33]}$ This nascent knowledge is, however, sufficient to support the position that public health strategies should incorporate sex, gender, age and other vulnerability considerations early in COVID-19 responses. ${ }^{[22]}$

The two-step flow theory and its later conceptualisations were applied to probe the utility of one-way communication via radio and television and two-way communication through social media to encourage dialogue about public health challenges among engaged audiences. Some claim that media audiences' discussion of health information is a prerequisite for its acceptance and impact on individual and group attitudes toward health recommendations. The theory informed the present examination of how young women in marginalised areas of eThekwini Metro receive health information, and with whom they discuss it to form and re-form opinions, with potential to influence prevailing health beliefs and norms in their primary circles.

It is important to anticipate how men, women and older and younger people may be differently affected by COVID-19, and how the multimorbidities of HIV, TB, diabetes, hypertension, malnutrition and overcrowded and unsanitary living conditions will influence the spread of the pandemic. Seven weeks after the advent of COVID-19 in KZN, there were already indications that these considerations would be significant to the infection and mortality rates in the province. Despite being the province with the third-highest number of people with COVID-19 - after Gauteng (1 170) and the Western Cape (940) - on 20 April, KZN (with 639) had the highest number of people who had died of COVID-19. ${ }^{[6]}$ Twenty-three out of 58 people who had succumbed were from KZN, 17 from the Western Cape and seven from Gauteng. ${ }^{[6]}$

\section{Ethical clearance}

The study was cleared by the University of KZN Biomedical Ethics Research Committee (ref. no. BE379/17). Authorisation to conduct research in KZN was granted by the Provincial Department of Health (NHRD ref. no. KZ_201711_047).

\section{Data collection}

Primary data were collected from 20 participants in eThekwini Metro, KZN, between 6 March and 29 September 2018. Data collection was done through 11 in-depth interviews and 3 focus-group discussions with between 4 and 5 purposefully selected participants. Data collection was triangulated through a multipronged recruitment strategy and research methods. An inductive approach to research sampling, data collection, analysis and presentation was also adopted. Ten of the research participants comprised the case study of the research: women aged 18 - 34 years from low socioeconomic status communities being treated for transmitted MDR-TB at a public hospital in the metro.

\section{Results}

It is significant that all 20 participants - 10 women being treated for MDR-TB, 3 family members/treatment supporters, 3 KZN Department of Health TB Management Programme senior staff, 3 nurses and 1 community health promoter - were women. Except for the women with transmitted MDR-TB, the selection criteria did not specify the sex of participants. Notwithstanding the small sample size, the representation of women on the final list illustrates women's significant participation in public health on both sides and at all levels in SA. This finding adds impetus to calls to understand how women will be impacted by COVID-19, and to proffer evidence on how to reach them with health education and services.

SA has high mass media penetration - television (83.4\%), radio (67.9\%) and mobile phone technology (93.8\%) ${ }^{[34]}$ - and thus mass and social media are viable mediums for health promotion. Residents of marginalised areas are more likely to own or have access to radios than televisions. A participant explained that MDRTB content:

'should be [broadcast] on both TV and radio because not all of us have a TV and not all of us listen to radio ... it should be everywhere.' (Nokuthula, 24 years, focus group 1, 26 May 2018)

Participants were, however, more likely to recall MDRTB information consumed on television than via any other medium. Interviews with medical experts on television news programmes on the SABC 1 channel were the most commonly recalled content. Indeed, Tichenor et al. ${ }^{[35]}$ found that local news programmes are most effective at closing knowledge gaps because local audiences are more invested in the information as it is relatable and directly impacts their lives. This finding urges countries to focus on communicating locally, and rely less on international media to produce health information for local audiences, as foreign content is less effective at influencing health attitudes and behaviours.

The study found that including a public health storyline into established local soap operas or dramas can increase young women's reception and retention of information, and increase the chances that they will act on it. A participant explained her typical television consumption during prime time as being centred around soap operas. She explained:

'I don't do radio, sorry. On TV I watch all the channels, see. At $18 \mathrm{~h} 30$ I watch "Skeem Sam" on eTV, at $19 \mathrm{h00} \mathrm{"Isidingo"}$ on SABC 3, then "Scandal" on eTV at 19h30, "Generations" at 20h00, "Uzalo" at 20h30, then "Muvhango" at 21 h00. I watch "iMbewu" on eTV from $21 \mathrm{~h} 30$ to 22h00.' (Nokuthula, 24 years, focus group 1, 26 May 2018) 
Linked to this, another participant suggested:

'... [insert a TB storyline] into soapies like "Uzalo", "Isibaya" and "The Queen"... use celebrities. People look up to them. They [audiences] like to do the things that they [celebrities] do. People listen to them!' (Nothando, 31 years, interview, 29 September 2018)

In SA, local soap operas have high viewership, and can support public health promotion efforts because the more media content reflects the cultures and contexts of viewers, the more confident audiences can be that it is possible to implement recommended remedies. As indicated in the quotation above, young women also respond positively to information shared by admired celebrities and actors. This contribution is important to consider when deciding who should front local public health promotion programmes.

Advertorials or public service announcements broadcast during popular local programmes can also be effective. It should, however be noted that repetition of advertisements to reach the same people more frequently is counterproductive, as some viewers report avoiding repetitive advertorials. A participant explained her consumption of advertorials during soap operas in the evenings by saying:

'Personally, I don't watch adverts. As soon as there is an advert break, I go to the kitchen' (Nokuthula, 24 years, FGD\#1, 26 May 2018).

New media support the sharing and discussion of health information received via other channels among geographically and culturally varied groups, which transcends Katz and Lazarsfeld's $s^{[20]}$ narrow conceptualisation of media audiences' primary circles as geographically defined. In this new conceptualisation, online gatekeepers share and encourage the recirculation of information via new media, and opinion-makers shape prevailing ideas and attitudes through sharing and discussing content. This is illustrated in one interviewee's explanation of the confluence of mass and social media, and how audiences make meanings from soap opera and drama texts. She explained that in SA:

"There are a lot of the "homebrewed" series that have a very wide audience at prime time. There are lots of conversations about characters in the episodes, so if that can be utilised, and not as a once-off, but maybe over five series, then maybe people in the street will be talking about 'did you see so and so in the film, let's say "Mkubaya" as an example ... on Twitter there will be national conversations about shows or people just having conversations. So we need to utilise those platforms. People do a lot of watching of television and they converse a lot about the characters, especially if it's the main characters.' (N Ngomane, clinical/technical advisor, Tuberculosis Control Programme, KwaZulu-Natal Department of Health, interview, 10 April 2018)

Finally, children emerged as important opinion-makers of health information for women who participated in the study. Many reported that their knowledge of and attitudes towards health information are most strongly influenced by knowledge shared by their children, especially if the information was received at school as part of the curriculum. One respondent explained:
I'm a parent, so when my child comes with homework, I obviously help him. If it's something that I don't know, I ask mom. If she isn't able to help, I will Google it, in that way the information is shared.' (Nokuthula, 24 years, focus group 1, 26 May 2018)

This finding suggests that there is potential to achieve a multi-step flow of health information, as several people engage with and discuss the learner's homework, with benefits for multiple household members. This finding is worth considering, as the impacts of health promotion could be improved through incorporating childfriendly information and formats, disseminating COVID-19 infection prevention messages via schools, colleges and universities, and engaging children through education entertainment that they will be excited to recirculate.

To be effective, public health promotion in low socioeconomic status contexts must utilise several mediums and channels, and be sustained enough to saturate the airwaves with interesting messages over a long period of time, as outlined in Fig. 2 and discussed below.

\section{Discussion}

This article contributes to public health scholarship on COVID19 responses in Africa. It privileges the importance of public participation and sustained individual, household and community actions to reduce the transmission of COVID-19 in low socioeconomic status contexts, and the primacy of public health promotion in achieving this. Public health promotion is a critical yet often underrated strategy, which can significantly contribute to protecting national investments in biomedical responses to communicable diseases in marginalised communities. ${ }^{[19]}$ To be effective, however, interventions must be informed by mapping of popular communication channels, and an understanding of how different groups prefer to receive health information and who the most influential people are to disseminate it.

Mass and social media can help to improve individual and group attitudes, health-seeking behaviour and uptake of health screening services. Once public knowledge about COVID-19 is better established, the next step would be to incorporate more strategies, including interpersonal communication in healthcare facilities and communities, and through educational curricula, to increase knowledge of COVID-19 infection, prevention and treatment. This is important for influencing public attitudes, as the first step in encouraging positive behaviour change.

In the case of a new pandemic such as COVID-19, it is vital to promote accurate information about SARS-CoV-2 symptoms and infection prevention, explain the influence of immunosuppression and comorbidity on susceptibility to infection and serious illness, and clearly communicate the vulnerabilities of different groups. Concurrently, it must be considered that for many, cultural beliefs and practices, and traditional leaders, influence health-seeking behaviour and acceptance of biomedical health services. These influences often mediate the acceptance (or not) of information about the aetiology of a disease and its treatment. It is therefore worth ensuring that the pathology of COVID-19 is explained in 


\section{RESEARCH}

\section{$\dot{\mathbf{I}}$}

Information taught as part of educational curriculum

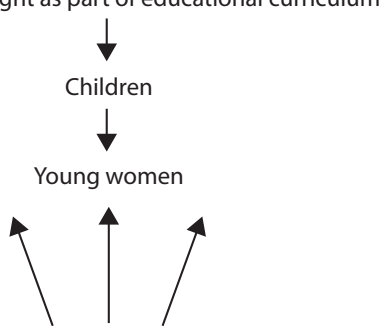

$((p))$

Experts, health workers, survivors and celebrities

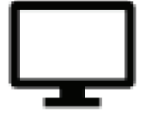

Television Evenings and prime time - Character on popular soap opera storyline - Local dramas - News programme

SABC 1, 2, 3 and eTV

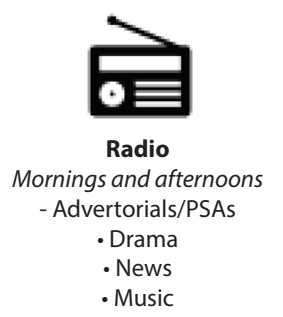

Izwi Lomzansi, East Coast Radio Gagasi FM, Inanda FM, Ukhozi FM,

Ntuzuma FM, LesediFM

Fig. 2. Public health promotion approach via mass and social media. (PSA = public service announcement).

ways that are easy for communities to understand within their cultures, as not doing so might threaten prevention and treatment efforts.

\section{Conclusion}

In SA and countries in Africa with high HIV and TB rates, youth bulges and large populations that live in overcrowded housing, but with high mass media and mobile network penetration, TB studies may lend insight to public health efforts to increase knowledge for improved success in COVID-19 prevention efforts. This article has shared lessons from public health promotion in the TB/DR-TB programme in SA, and applied them to the COVID-19 response. The approach complements the SA government's strategy, which anchored some biomedical components of its COVID19 programme on existing TB management strategies and infrastructure early in the response. For instance, GeneXpert machines used for TB diagnosis were repurposed to increase COVID-19 testing capacity. ${ }^{[36]}$

Further, global speculation about whether the Bacillus Calmette-Guerin (BCG) TB vaccine has protective effects for COVID-19 ${ }^{[37]}$ also supports the idea of examining how TB programmes can inform COVID-19 responses in countries with epidemics. This recommendation should, however, be read within the context of concerns that the shift of focus onto COVID19 and the marshalling of TB resources to the response has resulted in worrying reductions in TB testing and treatment, which has put patients at increased risk of mortality. ${ }^{[33]}$ It is, however, vital that while they have prominence, COVID-19 responses should adopt a comprehensive health promotion approach that includes existing health challenges such as HIV, TB, MDR-TB and diabetes in SA.

In concluding, while the recommendations in this paper are specific to SA's response, they might be applicable to countries with similar characteristics. It is also important to signpost here that COVID-19 requires a regional and global approach. Responses in Africa must transcend national interests, as no country will successfully halt the pandemic unless its neighbours have the capacity to do the same. Interconnections and mutual reliance mean that even if COVID-19 is well managed in one country, transboundary infections are likely to occur once travel restrictions are lifted, and so responses need to be less country-centric.

Acknowledgements. I acknowledge, with gratitude, the contributions of all participants to this study.

Author contributions. Sole author.

Funding. None

Conflicts of interest. None.

1. Lai CC, Shih TP, Ko WC, Tang HJ, Hsueh PR. Severe acute respiratory syndrome coronavirus 2 (SARS-CoV-2) and coronavirus disease-2019 (COVID-19): The epidemic and the challenges. Int J Antimicrob Agents 2020;55(3): 105924 https://doi.org/10.1016/j.jjantimicag.2020.105924

2. Ebenso B, Otu A. Can Nigeria contain the COVID-19 outbreak using lessons from recent epidemics? Lancet Glob Health 2020;8(6):e770. https://doi.org/10.1016/ s2214-109x(20)30101-7

3. Gilbert M, Pullano G, Pinotti $F$, et al. Preparedness and vulnerability of African countries against importations of COVID-19: A modelling study. Lancet 2020;395(10227):871-877. http://doi.org/10.1016/501406736(20)30411-6

4. Kiefer P. Genetic tracking helped us fight Ebola. Why can't it halt COVID-19? Five Thirty Eight, April 2020. https:/ fivethirtyeight.com/features/genetic-tracking-helpedus-fight-ebola-why-cant-it-halt-covid-19/ (accessed 23 April 2020).

5. Kiewit L. Health department confirms South Africa's first Covid-19 case. Mail \& Guardian, 5 March 2020. https:// mg.co.za/article/2020-03-05-health-departmentconfirms-south-africas-first-covid-19-case/ (accessed 20 April 2020)

6. Komorant. COVID-19 update: SA sees an increase of 142 cases in one day, with four more deaths also recorded. Komorant, April 2020

7. Karim SA. The South African response to the COVID 19 pandemic. Data@breakfast presentation. Durban: University of KwaZulu-Natal, 2020.

8. Vaugh A. We don't know why so few COVID-19 cases have been reported in Africa. New Scientist, March 2020. https://www.newscientist.com/article/2236760we-dont-know-why-so-few-covid-19-cases-have-beenreported-in-africa/ (accessed 12 April 2020).

9. Dupoux P, Larson J, Unnikrishnan S, Woods W. Fighting COVID-19 in Africa will be different. BCG, 26 March 2020. https://www.bcg.com/publications/2020/fighting-covidin-africa.aspx (accessed 23 April 2020).

10. Statistics South Africa. Statistical release P0309.3. Mortality and causes of death in South Africa, 2016: Findings from death notification. Pretoria: StatsSA, 2018. http://www.statssa.gov.za/publications/P03093/ P030932016.pdf. (accessed 6 May 2020) 
11. World Health Organization. Global tuberculosis report 2016. Geneva:WHO, 2016. https:// www.afro.who.int/sites/default/files/2017-06/9789241565394-eng.pdf (accessed 20 February 2017)

12. Shah NS, Auld SC, Brust JCM, et al. Transmission of extensively drug-resistant tuberculosis in South Africa. N Engl J Med 2017;376(3):243-253. https://doi.org/10.1056/NEJMoa1604544

13. Maharaj J, Ross A, Maharaj NR, Campbell L. An overview of patients' reported knowledge and attitudes. Afr J Prim Health Care Fam Med 2016;8(1):a1089. https://doi.org/10.4102/ phcfm.v8i1.1089

14. Mugoni PC. (Re)positioning communication for enhanced multidrug-resistant tuberculosis treatment adherence in South Africa. Towards an integrated communication model for young women. PhD thesis. Durban: University of KwaZulu-Natal, 2019 https://researchspace.ukzn.ac.za/xmlui/bitstream/handle/10413/16596/Petronella Mugoni 2019.pdf? sequence=1\&isAllowed=y (accessed 25 March 2020).

15. Statistics South Africa. National and provincial labour market: Youth, Quarter 1. Pretoria: StatsSA, 2015. http://www.statssa.gov.za/publications/P02114.2/P02114.22015.pd (accessed 24 June 2017).

16. O'Donnell MR, Daftary A, Frick M, et al. Re-inventing adherence: Toward a patient centred model of care for drug-resistant tuberculosis and HIV. Inter J Tuberc Lung Dis 2016;20(4):430-434. https://doi.org/10.5588\%2Fijtld.15.0360

17. World Health Organization. Global Tuberculosis Report 2018. Geneva: WHO, 2018. http:// apps.who.int/iris/bitstream/handle/10665/274453/9789241565646-eng.pdf (accessed 20 September 2018)

18. Department of Health, KwaZulu-Natal. 2015/2016 annual report. Durban: KZN DoH, 2016 http://www.kznhealth govza/2015-2016-Annual-Report.pdf (accessed 31 August 2017).

19. Flaskerud JH, Winslow BJ. Conceptualizing vulnerable populations health-related research Nurs Res 1998;47(2):69-78. https://doi.org/10.1097/00006199-199803000-00005

20. Katz E, Lazarsfeld PF. Personal Influence: The Part Played by People in the Flow of Mass Communications. Glenco, IL: Free Press, 1955.

21. Southwell BG, Yzer MC. The roles of interpersonal communication in mass media campaigns. Ann Int Comm Assoc 2007;13(1):420-462.

22. Smith J. Overcoming the 'tyranny of the urgent': Integrating gender into disease outbreak preparedness and response. Gender Dev 2019;27(2):355-369. https://doi.org/10.1080/13 552074.2019 .1615288

23. Theobald S, Morgan R, Hawkins K, Ssali S, George A, Molyneux S. The importance of gender analysis in research for health systems strengthening. Health Policy Plan 2017;32:13. https://doi.org/10.1093/heapol/czx163

24. Koniak-Griffin D, Flaskerud JH, Nyamathi A. Vulnerable populations research: A center for excellence. In: de Chesnay M (editor). Caring for the Vulnerable: Perspectives in Nursing Theory, Practice, and Research. Sudbury, MA: Jones \& Bartlett, 2005.
25. Van Rensburg D, van Rensburg-Bonthuyzen EJ, Heunis C, Meulemans H. Tuberculosis control in South Africa: Reasons for persistent failure. Acta Academica Supplementum 2005;1:1-55.

26. Grabovschi C, Loignon C, Fortin M. Mapping the concept of vulnerability related to health care disparities: A scoping review. BMC Health Serv Res 2013;13(1):94. https://doi. org/10.1186/1472-6963-13-94

27. Vlassoff C. Gender differences in determinants and consequences of health and illness. J Health Popul Nutr 2007;25(1): 47-61.

28. World Health Organization. Coronavirus. Geneva: WHO, 2020. https://www.who.int/ health-topics/coronavirus\#tab=tab_1\%0D (accessed 20 April 2020).

29. The Union. COVID-19 and lung health: Frequently asked questions. The Union, 2020 http://origin.theunion.org/news-centre/covid-19/covid-tb-fags (accessed 20 April 2020).

30. Devlin H. Men are much more likely to die from coronavirus - but why? The Guardian 16 April 2020. https://www.theguardian.com/world/2020/mar/26/men-are-much-morelikely-to-die-from-coronavirus-but-why (accessed 26 April 2020)

31. Global Health Tracker. Covid-19 sex disaggregated data. Global Health Tracker, 2020. https://globalhealth5050.org/covid19/ (accessed 25 April 2020).

32. Fidler S, Stöhr W, Pace $M$ et al. Antiretroviral therapy alone $v$ antiretroviral therapy with a kick and kill approach, on measures of the HIV reservoir in participants with recent HIV infection (the RIVER trial): A phase 2, randomised trial. Lancet 2020;395(10227):888-898 https://doi.org/10.1016/s0140-6736(19)32990-3

33. Steyn D. We must never forget TB is still out there. Daily Maverick, 27 April 2020. https:// www.dailymaverick.co.za/article/2020-04-27-we-must-never-forget-tb-is-still-out-there/ (accessed 30 April 2020).

34. Treffry-Goatley A. Jiving and driving: Taxi drivers, HIV and edutainment in rural KwaZuluNatal, South Africa. J Global Health 1 April 2017.

35. Tichenor PJ, Donohue GA, Olien CN. Mass media flow and differential growth in knowledge. Public Opinion Q 1970;34(2):159-170.

36. National Institute of Communicable Diseases. Covid-19 update, 27 March 2020. Pretoria: NICD, 2020. https://www.nicd.ac.za/covid-19-update-26/. (accessed 10 April 2020).

37. Hegarty PK, Service NH, Kamat AM, Dinardo A. BCG vaccination may be protective against Covid-19. ResearchGate 2020;(March):(epub ahead of print). https://doi.org/10.13140/ RG.2.2.35948.10880

Accepted 18 June 2020 